\title{
In House Training Pengembangan Kompetensi Guru Sekolah Dasar melalui Basic Literacy dan Literasi Matematika Model Pisa
}

Dedi Kusnadi' , A. Wilda Indra Nanna ${ }^{2}$, Mety Toding Bua ${ }^{3}$, Ady Saputra4, Irianto Aras ${ }^{5}$

1,2,3,4,5Jurusan Pendidikan Guru Sekolah Dasar, Fakultas Keguruan dan Ilmu Pendidikan, Universitas Borneo Tarakan, Tarakan, Kalimantan Utara

Email: dedikusnadi4289@gmail.com

\begin{abstract}
Article Info
Article History

Received: 2021-11-20

Revised: 2021-12-15

Published: 2022-01-03

Keywords:

Teacher Competence;

Basic Literacy;

Mathematical Literacy;

Pisa model.

Abstract

The implementation of literacy in the teaching and learning process does not merely focus on the role of the students only. However, teachers also have the capacity as facilitators to have an important role in assisting and encouraging the enhancement of the culture of literacy in the educational environment, particularly in the learning process. The main purpose of this community service is to implement innovations in learning based on basic literacy and mathematical literacy of the PISA model into learning instruments and apply these aids in the classroom. The targets and outcomes of this community service activity are to increase the understanding and experience of teachers in creating literacy-based learning and to produce learning aids that have two forms; lesson plans and literacy-based learning media, big books. The application of in-house training activities for teacher competency development in the use of literacy through three stages 1) providing information in the form of workshops, 2) assisting in the preparation of lesson plans, big book media and assessments, and 3) implementing learning instruments that have been prepared.
\end{abstract}

\begin{tabular}{l}
\hline Artikel Info \\
\hline Sejarah Artikel \\
Diterima: 2021-11-20 \\
Direvisi: 2021-12-15 \\
Dipublikasi: 2022-01-03
\end{tabular}

Kata kunci: Kompetensi Guru; Literasi Dasar; Literasi Matematika; Model Pisa.

\begin{abstract}
Abstrak
Penerapan literasi selama proses pembelajaran tidak hanya fokus pada peran para peserta didik semata. Akan tetapi, guru juga memiliki kapasitas sebagai fasilitator yang memiliki tugas penting dalam membantu dan mendorong meningkatkan budaya literasi di lingkungan pendidikan, khususnya dalam proses pembelajaran, Tujuan dilaksanakan pengabdian ini adalah untuk menerapkan inovasi dalam pembelajaran berupa pembelajaran yang berbasis literasi dasar dan literasi matematika model PISA ke dalam perangkat pembelajaran dan mengimplementasikannya dalam proses pembelajaran di kelas. Target dan luaran dari kegiatan pengabdian ini adalah peningkatan pemahaman dan pengalaman guru dalam menciptakan pembelajaran yang berbasis literasi dan menghasilkan perangkat pembelajaran berupa RPP dan media pembelajaran berbasis literasi dalam bentuk big book. Pelaksanaan kegiatan in house training pengembangan kompetensi guru melalui pemaanfaatan literasi ini melalui tahapan 1) pemberian informasi dalam bentuk workshop, 2) pendampingan penyusunan RPP, media big book dan penilaian dan 3) implementasi perangkat pembelajaran yang telah disusun.
\end{abstract}

\section{PENDAHULUAN}

Menatap masa depan yang serba terbuka, penguasaan keterampilan literasi sangat penting. Saat ini masyarakat dituntut untuk memanfaatkan pengetahuannya secara optimal agar lebih cerdas dan kritis dalam menerima dan mengolah informasi. Literasi merupakan sebuah keterampilan dalam mengakses, memahami dan menggunakan informasi secara cerdas. Literasi dapat membantu siswa memahami teks lisan, tulisan, audio maupun gambar/visual. Melalui literasi, siswa dapat terdidik dengan baik (Suragangga, 2017). Kemampuan literasi menjadi kemampuan penting yang harus dikuasai agar bisa hidup dan berkehidupan pada abad ke-21 ini (Sari, 2018), Data dari UNDP tahun 2014 melalui buku desain induk gerakan literasi sekolah mencatat bahwa tingkat kemelekhurufan masyarakat Indonesia mencapai 92, $8 \%$ untuk dewasa dan 98,8\% untuk kategori remaja. Capaian ini menunjukkan bahwa Indonesia telah melewati tahapan krisis literasi (Susilo). Akan tetapi hal ini berbanding terbalik dengan hasil penelitian dari central connectitut state university tahun 2016, yang menempatkan peringkat literasi Indonesia berada di urutan 60 dari 61 negara. Survey yang mengevaluasi kemampuan peserta didik yang dilakukan oleh Programme for International Student Assesment (PISA) yang mencakup membaca, matematika dan sains juga menunjukkan hasil kurang memuaskan. Hasil studi PISA tahun 2015 menunjukkan Indonesia baru bisa menduduki peringkat 69 dari 76 negara (litbang.kemdikbud.go.id). Sementara itu, di 
Kalimantan Utara, AKSI menemukan kemampuan membaca siswa kelas IV SD berada dua point di bawah nilai rata-rata nasional.

Hasil penelitian di atas menunjukkan bahwa terindikasi kurangnya kemampuan literasi peserta didik masih di bawah rata-rata dan perlu mendapatkan perhatian khusus. Dan untuk menyikapi hal tersebut Kementerian Pendidikan dan Kebudayaan telah mengembangkan Gerakan Literasi Sekolah. Selain melalui Gerakan Literasi Sekolah, kompetensi guru dalam proses pembelajaran juga patut untuk diperhatikan. Berdasarkan hasil penelitian yang dilakukan oleh Susilo diperoleh informasi bahwa salah satu faktor penghambat pelaksanaan literasi sekolah dari segi internal yakni berasal dari guru yang tidak literat.

Hasil observasi awal di SD mitra memberikan hasil antara lain: a) SDN 045 telah mengenal literasi melalui Gerakan Literasi Sekolah kemudian menerapkan dalam kegiatan membaca 15 menit sebelum pembelajaran dimulai tetapi belum memasukkan literasi ke materi pembelajaran di kelas; b) Literasi dasar yang diketahui oleh guru dalam bentuk membaca dan memahami bacaan tapi belum diterapkan dalam proses pembelajaran; c) Guru- Guru belum mengenal literasi dalam pembelajaran matematika; d) Dari 10 orang guru yang pernah mengiktu Uji Kompetensi Guru (UKG) hanya 2 orang guru yang lulus dengan nilai KKM 55 yakni pada tahun 2015, sementara untuk tahun 2016 dan 2017 belum ada guru yang lulus.

SDN 045 Tarakan adalah Salah satu sekolah yang berada di wilayah pesisir dan terletak jauh dari pusat Kota Tarakan. Berikut ini gambaran fisik (keadaan sekolah) yang menjadi mitra dalam kegiatan pengabdian pada masyarakat yang terekam dari hasil observasi, keberhasilan dalam pembelajaran bukan sesuatu yang kebetulan melainkan karena ada sebuah usaha yang dilakukan. Sutama (2016) menjelaskan bahwa guru sebagai ujung tombak di lapanagan mempunyai peranan yang sangat menentukan dalam peningkatan mutu pendidikan. Mengacu pada pembelajaran kurikulum 2013 dimana guru sebagai fasilitator dan siswa sebagai subjek pembelajaran maka kegiatan literasi sudah selayaknya tidak berfokus pada siswa saja tetapi guru harus memiliki peran andil dalam menciptakan peserta didik yang literat. Guru harus menjadi fasilitator yang berkualitas untuk mencetak peserta didik yang cerdas dan generasi yang gemilang.
Memperhatikan beberapa fakta yang terjadi, permasalahan-permasalahan yang terjadi di bidang pendidikan dan kesehatan, maka tim bersama dengan Kepala Sekolah SDN 045 Tarakan menimbang perlu untuk memprioritaskan permasalahan nyata yang dihadapi oleh guru-guru, diantaranya:

1. SDN 045 telah mengenal literasi melalui Gerakan Literasi Sekolah kemudian menerapkan dalam kegiatan membaca 15 menit sebelum pembelajaran dimulai tetapi belum memasukkan literasi ke materi pembelajaran di kelas;

2. Literasi dasar yang diketahui oleh guru dalam bentuk membaca dan memahami bacaan tapi belum diterapkan dalam proses pembelajaran;

3. Guru- Guru belum mengenal literasi dalam pembelajaran matematika;

Hal yang perlu dilakukan untuk mencetak generasi yang literat dan membangun ketertarikan siswa dalam pembelajaran di kelas adalah dengan menerapkan pembelajaran yang berbasis literasi. Alternative tindakan yang bisa ditawarkan berdasarkan permasalahan mitra di SDN 045 Tarakan sebagai sekolah mitra yaitu perlu ada inovasi dalam pembelejaran di kelas, salah satu inovasi yang bisa dilaksanakan adalah melalui pembelajaran berbasis literasi dengan menerapkan literasi dasar dan literasi matematika model PISA ke dalam perangkat pembelajaran dan mengimplementasikannya dalam proses pembelajaran di kelas, memperhatikan permasalahan prioritas yang dihadapi mitra, tim bersama dengan Kepala Sekolah merumuskan kegiatan dalam bentuk pelatihan dan pendampingan guru dengan tujuan menambah wawasan dan pengetahuan guru terkait pembelajaran berbasis literasi, meningkatkan keterampilan guru dalam menyusun perangkat pembelajaran berbasis literasi, dan dapat melaksanakan tugasnya sehari-hari di kelas secara lebih professional sehingga pada akhirnya mutu pendidikan kita dapat lebih terjaga dan terus meningkat dalam bentuk Program Pengabdian Kepada Masyarakat (PKM)

\section{METODE PENELITIAN}

Menyesuaikan dengan permasalahan mitra di SDN 045 Tarakan sebagai sekolah mitra maka metode pelaksanaan kegiatan dengan melakukan analisis situasi pembelajaran berbasis literasi melalui penerapan literasi dasar dan literasi matematika model PISA ke dalam perangkat pembelajaran dan mengimplementasikannya dalam proses pembelajaran di kelas. Pelaksaanan kegiatan ini dimulai pada tanggal 14 September - 
31 Oktober 2018 denngan melalui tahapan sebagai berikut:

a. Workshop literasi matematika model PISA dan basic literacy dalam proses belajar mengajar. Workshop ini dilaksanakan di SDN 045 Tarakan pada tanggal 21 September 2018 diikuti oleh peserta dari guru-guru berjumlah 15 orang. Tim pengabdian berjumlah 3 orang dibantu oleh tenga lapangan 3 orang yang terdiri dari 2 mahasiswa dan 1 orang dosen.

b. Pendampingan penyusunan rencana pelaksanaan pembelajaran (RPP),Media pembelajaran Big Book, instrumen penilaian proses dan hasil belajar yang berbasis basic literacy dan literasi matematika model PISA. Kegiatan ini dilaksanakn pada saat workshop kemudian dilanjutkan sebanyak 3 (tiga) kali pertemuan. Pendampingan ini lebih menfokuskan kepada perwakilan guru kelas tinggi dan guru kelas rendah yang telah disepakati bersama pada saat workshop.

Implementasi literasi matematika model PISA dan basic literacy dalam proses pembelajaran di kelas. Kegiatan ini dilaksanakan selama 1 (satu) hari. Tim bersama dengan guru yang telah didampingi dalam penyususunan perangkat pembelajaran berbasis literasi mempraktekkan RPP dan media big book pada siswa kelas II dan siswa kelas IV SDN 045 Tarakan.

\section{HASIL DAN PEMBAHASAN}

Kegiatan in house training pengembangan kompetensi guru sekolah dasar melalui pemanfatan basic literacy dan literasi matematika model PISA dilaksanakan melalui tiga tahapan. Tahapan pertam yakni pelaksanaan worksop pembelajaran berbasis literasi. Pada workshop pembelajaran berbasis literasi ini diikuti oleh guru kelas dengan jumlah 15 orang. Materi yang disampaikan pada kegiatan workshop ini adalah tentang mengapa literasi itu penting, strategi membangun budaya literasi dan media pembelajaran literasi, melalui kegiatan workshop ini diperoleh informasi bahwa guru-guru sedang gencar melaksanakan program Gerakan Literasi Sekolah dalam tahap pembiasaan. Tahap pembiasaan yang dimaksud adalah mengupayakan agar siswa bisa membaca selama 15 menit di awal pembelajaran. Akan tetapi, guru belum sampai pada tahap pembelajaran. Sehingga bisa disimpulkan guru belum terbiasa melaksanakan proses belajar mengajar dengan menerapkan literasi.

Media pembelajaran yang digunakan oleh guru-guru lebih banyak menggunakan sumber bacaan dari buku paket ataupun buku siswa. Beberapa guru sudah tahu tentang media literasi yang berbentuk big book, hanya saja belum ada guru yang menyusun big book sendiri dengan menyesuaikan materi yang akan diajar dan kondisi siswa. Dari hasil pengamatan tersebut diputuskan selain menyusun RPP berbasis literasi juga akan membuat big book dengan menyesuaikan kondisi di kelas. Peserta workshop dibagi ke dalam 3 (tiga) kelompok, masing-masing kelompok mendapatkan tugas untuk memilih indikator sesuai RPP yang disusun dan menuankan ide cerita mereka ke dalam bentuk big book. Di akhir kegiatan peserta memilih dua orang guru yang mewakili guru kelas tinggi dan guru kelas rendah untuk mengikuti kegiatan pendampingan yang dilaksanakan di luar workshop denngan tujuan melanjutkan penyusunan RPP dan big book.

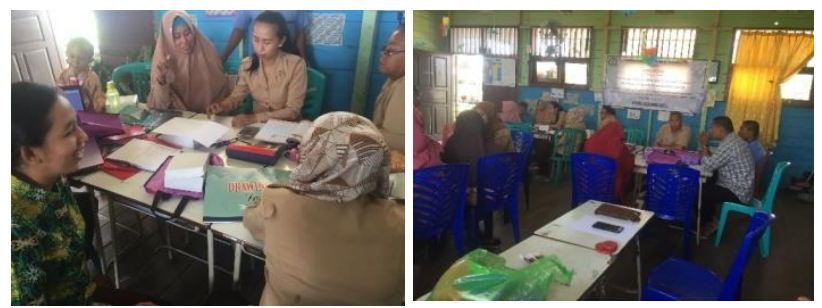

Gambar 1. Workshop pembelajaran literasi

Kegiatan berikutnya ini merupakan lanjutan dari workshop. Sebanyak 2 (dua) orang guru didampingi dalam menyusun RPP dan menyelesaikan big book pada sesi workshop sebelumnya. Kegiatan ini dilaksanakan sebanyak 3 kali pertemuan samapai perangkat pembelajaran siap untuk diimplementasikan dalam proses pembelajaran di kelas. Pada saat kegiatan pendampingan, guru sudah tidak menghadapi kesulitan yang begitu berarti karena telah mendapatkan teori dan ilmu pada saat worksop. Dari kegiatan pendampingan ini dihasilkan tiga buah big book yang siap untuk di desain dan di cetak.
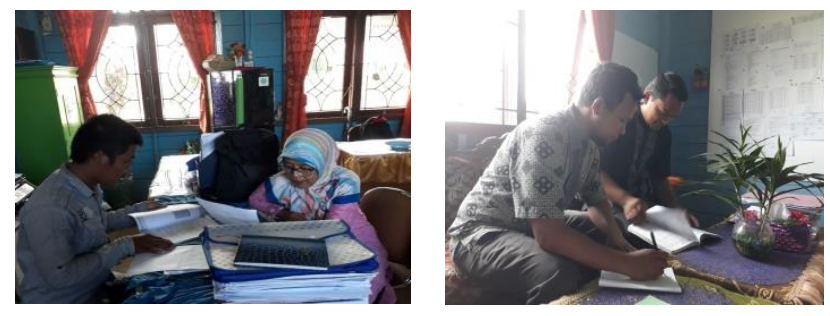

Gambar 2. Pendampingan penyusunan perangkat pembelajaran

Setelah tim menyelesaikan desain gambar dan mencetak big book kegiatan dilanjutkan berupa implementasi dalam pembelajaran. Kegiatan implementasi ini dilaksanakan pada dua kelas yakni siswa kelas II dan siswa kelas IV. Proses 
pembelajaran berjalan seperti biasa sesuai dengan RPP yang disusun, yang membedakan adalah media pembelajaran yang digunakan dalam bentuk cerita yang didalamnya terkait basic literacy dal literasi matematika model PISA. Antusiasme siswa sangat terlihat ketika proses pembelajaran di kelas. Siswa sangat tertarik mengamati gambar-gambar yang ada pada big book. Selain itu, siswa tidak merasa malu ketika diminta untuk menceritkan kembali apa yang telah mereka baca. Dari implementasi ini terlihat bahwa dengan media big book yang disusun dapat membuat iklim kelas menjadi aktif dan menyenangkan.

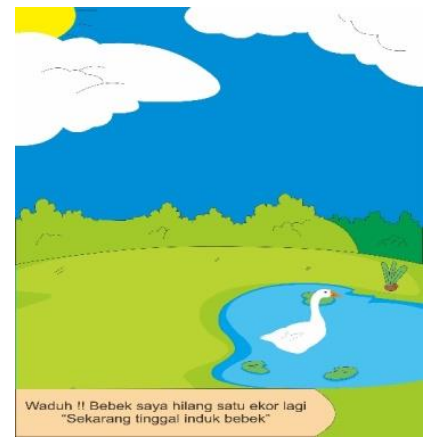

Gambar 3. Big book berbasis literasi

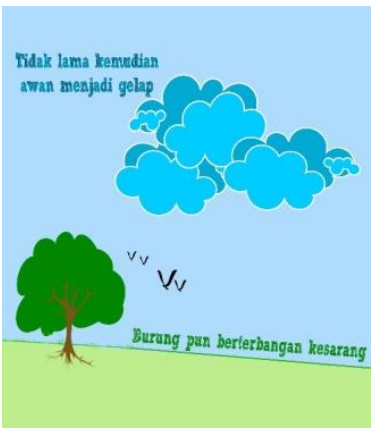

Gambar 4. Big Book dengan basic literacy
Pada Gambar 3 menunjukkan salah satu halaman pada big book yang telah disusun guru bersama tim. Media tersebut untuk membantu guru dalam menyampaikan materi matematika pada indikator atau pokok bahasan pengurangan bilangan. Untuk basic literacy dapat dilihat pada gambar 4 yang menunjukkan proses terjadinya hujan atau perubahan cuaca.

Berdasarkan kegiatan dan hasil pengabdian ini dapat disimpulkan bahwa target dan luaran dari kegiatan in house training pengembangan kompetensi guru sekolah dasar melalui pemanfaatan basic literacy dan literasi matematika model PISA telah tercapai. Hal ini ditandai dengan telah dilakasanakannya pertukaran informasi, wawasan dan pengalaman melalui kegiatan workshop dan produk berupa RPP berbasis literasi dan media pembelajaran big book.

\section{SIMPULAN DAN SARAN}

\section{A. Simpulan}

Rangkaian kegiatan yang dilaksanakan, bahwa kegiatan pengabdian pada masyarakat ini dalam bentuk workshop pembelajaran berbasis literasi, pendampingan penyusunan perangkat pembelajaran dan implementasi perangkat RPP dan media big book dalam pembelajaran di kelas. Melalui kegiatan telah membantu guru-guru di SDN 045 Tarakan yaitu guru dapat meningkatkan keterampilan dan wawasan dalam menerapkan pembelajaran berbasis literasi di dalam proses belajar mengajar di kelas, guru dapat menggunakan produk yang dihasilkan berupa RPP berbasis literasi dan big book berbasis basic literacy dan literasi matematika model PISA dalam proses pembelajaran, untuk meningkatkan kualitas pembelajaran di SDN 045 Tarakan selanjutnya diharapkan guru-guru bisa memulai untuk membuat media pembelajaran big book sesuai dengan ide cerita dan kondisi siswa di kelas masing-masing. dan guru dapat menerapkan pembelajaran dikelas dengan berbasis literasi.

\section{B. Saran}

Beberapa saran yang diberikan berdasarkan hasil penelitian adalah (1) diharapkan kepada guru lebih memahami literasi matematika, Agar meningkatkan kemampuan siswa dalam menyelesaikan permasalahan matematika dalam kehidupan sehari-hari, (2) pengabdian ini perlu dilakukan lagi di sekolah-sekolah lain, agar guru guru dapat menerapkan literasi matematika ke dalam pembelajaran.

\section{UCAPAN TERIMA KASIH}

Ucapan terima kasih kami kepada LPPM Universitas Borneo Tarakan yang telah memberikan dana hibah pengbadian kepada masyarakat untuk melaksnakan Pelatihan di SDN 045 Tarakan. Tidak lupa pula kami ucapkan terima kasih tim pengabdian dan Kepala Sekolah SDN 045 yang bersedia memberikan waktu dan tempat untuk melaksanakan kegiatan.

\section{DAFTAR RUJUKAN}

Deny Diniyati. 2012. Meningkatkan Minat, Kemandirian Dan Prestasi Belajar Siswa Pada Pelajaran Matematika Melalui Pembelajaran Kooperatif Tipe Think Pair Share (TPS). Skripsi tidak diterbitkan, Universitas Muhammadiyah Purwokerto.

Fathani, Halim Abdul. 2016. Pengembangan Literasi Matematika Sekolah Dalam Perspektif Multiple Intelengences. EduSains Vol. 4. No.2. 2016

Huda, M. N., Mulyono, M., Rosyida, I., \& Wardono, W. 2019. Kemandirian belajar berbantuan mobile learning. PRISMA: Prosiding Seminar Nasional Matematika, 198-806. 
Retrieved

from

https://journal.unnes.ac,id/sju/index.php/ prisma/article/view/29270.

Ibrahim. 2012. Evaluasi Pembelajaran. Jakarta: Rhineka Cipta.

Melida Fitroturrohmah. 2019. Hubungan Peran Orang Tua Dengan Prestasi Belajar Siswa Kelas Tinggi SDN Kedung 01 Jepara. JANACITTA Journal of Primary and CHildren's Education.Vol 2, No 2.

Novantri, W., \& Aftriyati, L. W. 2020. Are Discovery Learning And Indipendent Learning Efective In Improving Students'cognitive Skill? Belajar Efektif Dalam Meningkatkan Kemampuan. Indonesia journal of science and mathematic Education, 03 (july), 144152,https:?//doi.org/10.2404.ijsme.v312.6 615.

Sari, Ika Fadilah Ratna, 2018. Konsep Dasar Gerakan Literasi sekolah Pada Permendikbud Nomor 23 Tahun 2015 Tentang Penumbuhan Budi Pekerti. AlBidayah: Jurnal Pendidikan Dasar Islam Volume 10 Nomor 1, Juni 2018. P-ISSN: 2085-0034, E-ISSN: 2549-3388.
Slameto. 2010. Belajar dan faktor-faktoryang Mempengaruhinya. Jakarta: Rineka Cipta.

Sudjana. 2004. Dasar-dasar Proses Belajar Mengajar. Bandung: Sinar Baru Setiawati. 2002. Optimalsasi Kegiatan Belajar Mengajar. Bandung: PT. Remaja Rosdakarya.

Suragangga, I Made Ngurah, 2017. Mendidik Lewat Literasi Untuk Pendidikan Berkualitas. Jurnal Penjaminan Mutu Lembaga Penjaminan Mutu Institut Hindu Dharma Negeri Depasar, Vol 3 No.2. 2017. http//ejournal.ihdn.ac.id/index.php/JPM

Susilo, Jimat. ...... Peran Guru Pembelajar sebagai Pegiat Gerakan Literasi Sekolah: Tantangan dan Solusi. EduSains Vol. 4. No.1

Sutama,2016. Darurat Pembelajaran Matematika: Guru Matematika Professional untuk Menyiapkan Generasi Emas. Makalah disajikan pada seminar nasional pendidikan matematika pada tanggal 15 Mei 2016 